\title{
Practice of Pain Management by Indian Healthcare Practitioners: Results of a Paper Based Questionnaire Survey
}

\author{
Gauri Billa, Mukesh Gabhane, and Swati Biswas \\ Abbott Healthcare Pvt. Ltd., 1st Floor, D Mart Building, Mulund-Goregaon Link Road, Mumbai 400080, India \\ Correspondence should be addressed to Gauri Billa; gauri.billa@abbott.com
}

Received 29 June 2015; Revised 8 August 2015; Accepted 12 August 2015

Academic Editor: Giustino Varrassi

Copyright ( 2015 Gauri Billa et al. This is an open access article distributed under the Creative Commons Attribution License, which permits unrestricted use, distribution, and reproduction in any medium, provided the original work is properly cited.

\begin{abstract}
Objective. Understanding factors while selecting an analgesic and its usage pattern by Indian healthcare practitioners (HCPs). Methods. Questionnaire-based survey was conducted among six healthcare specialties. Results. Total 448 HCPs participated. Patient's age $(72.8 \%, 74.4 \%, 87.5 \%$, and $78.9 \%)$ and duration of therapy $(70.8 \%, 66.2 \%, 69.6 \%$, and $73.6 \%)$ were main attributes for selecting an opioid according to general practitioners (GPs), dentists, consulting physicians (CPs), and surgeons, respectively. Patient's age was important factor while selecting NSAID according to $77.60 \%, 66.91 \%$, and $84.20 \%$ of GPs, dentists, surgeons, respectively. For mild pain, paracetamol was the choice according to $77 \%, 78.57 \%$ and $74 \%$ of GPs, CPs, and surgeons, respectively. For moderate pain, $77 \%, 87.50 \%, 68 \%$, and $80.30 \%$ of GPs, CPs, surgeons and orthopedicians, respectively, preferred the use of paracetamol + tramadol combination. For moderate pain, NSAID + paracetamol and paracetamol+diclofenac were used by $68.94 \%$ and $47.73 \%$ of orthopedicians, respectively. Lack of pain clinic (38.8\%) in city was commonly cited reason for not referring patients to pain clinics. Conclusion. Patient's age, duration of therapy, comorbid conditions, frequency of dosing, and severity of pain are important parameters while selecting analgesics. Paracetamol and its combinations are commonly used for mild and moderate pain, respectively. Pain clinics currently have limited presence in India.
\end{abstract}

\section{Introduction}

Regardless of age, sex, and region, pain is a significant health issue worldwide [1]. Everybody suffers from some type of pain during life time. Understanding pain as a disease [1], better diagnosis, and treatment may help to reduce overall health burden associated with pain. Currently, numerous nonpharmacological and pharmacological treatment options are available for the management of pain. The major pharmacological options include paracetamol, nonsteroidal antiinflammatory drugs (NSAIDs), and opioids. In many cases, combination of analgesics is required for effective pain relief. Unfortunately, no single agent is an ideal choice for all types of patients or no one agent is suitable for all types of pain [2]; hence physician has to choose the best suitable agent from the available options based on different factors including patient dynamics, medicine related factors, and disease related aspects. Patient satisfaction also plays an important role in ensuring compliance with the treatment, especially during long term treatment. Understanding physician's perspective while selecting an analgesic and significant barriers in effective pain management through a systematic approach and addressing them with appropriate measures could help for better outcomes.

\section{Objective}

The objective of this study was to understand the attributes for selection of analgesics and usage pattern of analgesics for different pain conditions by Indian healthcare practitioners (HCPs).

\section{Material and Methods}

A cross-sectional, paper based survey was conducted among HCPs across India. Healthcare professionals practicing in India were approached in their working set-ups for 
TABLE 1: Distribution of survey participants.

\begin{tabular}{lc}
\hline Specialty & $N(\%)$ \\
\hline General practitioners & $103(23.0 \%)$ \\
Consulting physicians & $56(12.5 \%)$ \\
Dentists & $133(29.7 \%)$ \\
Orthopedicians & $132(29.5 \%)$ \\
General surgeons & $19(4.2 \%)$ \\
Neurologists & $5(1.1 \%)$ \\
Total & $\mathbf{4 4 8 ( 1 0 0 \% )}$ \\
\hline
\end{tabular}

participation in the survey. A predefined questionnaire was administered to HPCs of six different disciples: general practitioners (GPs), consulting physicians (CPs), dentists, neurologists, orthopedicians, and general surgeons. The questions were divided into the following three sections:

(i) Factors considered while selecting opioids and NSAIDs.

(ii) Choices of different analgesics.

(iii) Limitations for referral of selected patients to the pain clinic.

Suggestions from HCPs for better pain management were also recorded. Completed survey forms were collected by the representatives of the company.

\section{Statistical Analysis}

The number and percentage of HCPs responses for each question were calculated. Missing data was not considered for calculating percentages. SPSS version 19.00 was used for the statistical analyses.

\section{Results}

A total of 448 healthcare practitioners across India were enrolled for participation in the study. Specialty-wise distribution of survey participants is given in Table 1 .

As neurologists constituted very small number of total survey population, the results from this discipline are not reported in this paper.

5.1. Factors Considered While Selecting an Opioid Agent. Patient's age, duration of therapy, comorbid conditions, and frequency of dosing were the main attributes for use of opioid according to $72.8 \%, 70.8 \%, 62.1 \%$, and $52.4 \%$ of GPs, respectively (Figure 1).

According to $92.8 \%$ of CPs, comorbid condition was the most important factor for selecting an opioid for analgesia. Patients age, duration of therapy, and frequency of dosing were considered as important parameters by $87.5 \%, 69.6 \%$, and $64.2 \%$ of CPs, respectively (Figure 2).

Patient's age, comorbid conditions, duration of therapy, and frequency of dosing were considered as main factors

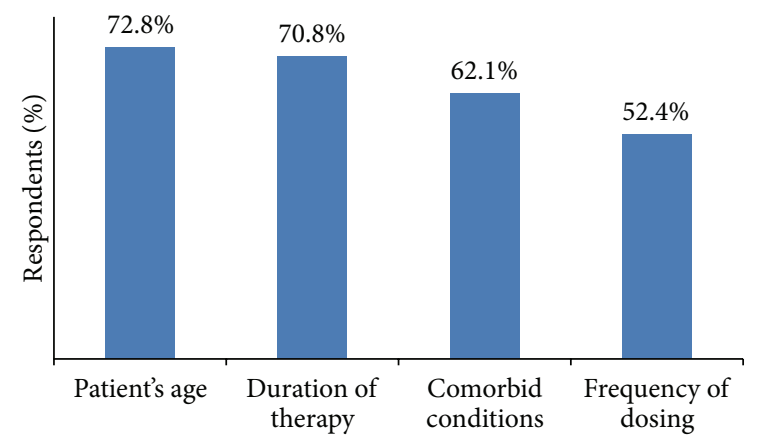

FIGURE 1: Factors considered by GPs while selecting opioids.

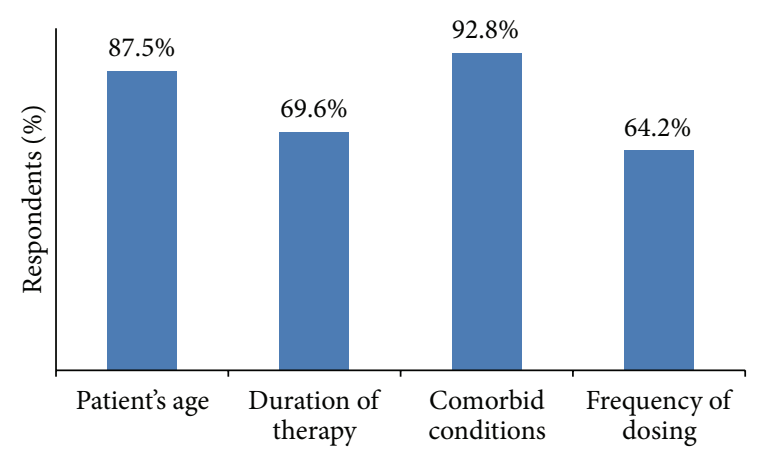

FIGURE 2: Factors considered by CPs while selecting opioids.

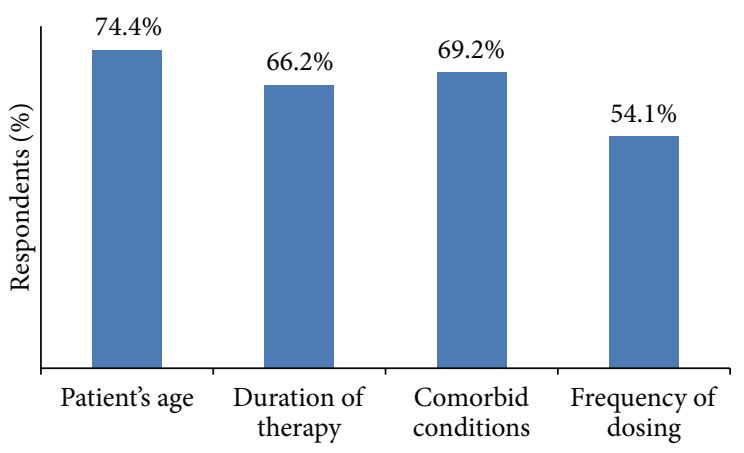

FIGURE 3: Factors considered by dentist while selecting opioids.

while selecting an opioid by $74.44,69.2 \%, 66.2 \%$, and $54.1 \%$ of dentists, respectively (Figure 3 ).

Patients age, duration of therapy, severity of pain, and frequency of dosing were the important attributes for selecting opioid analgesic according to $78.9 \%, 73.6 \%, 78.9 \%$, and $78.9 \%$ of general surgeons, respectively (Figure 4).

5.2. Factors Considered While Selecting NSAIDs. Patient's age $(77.6 \%)$, comorbid conditions $(70.8 \%)$, severity of pain (60.1\%), duration of therapy, frequency of dosing $(59.2 \%$ each), and other factors such as cost, gender, and social issues (2.9\%) were the major attributes reported by GPs while selecting NSAIDs (Figure 5). 


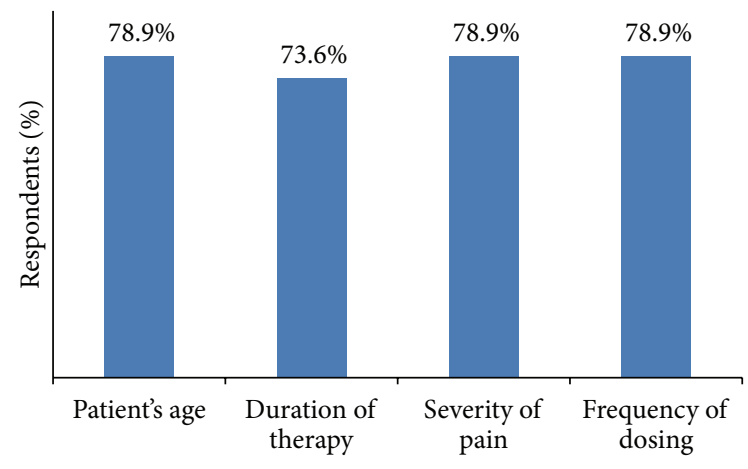

FIGURE 4: Factors considered by general surgeons while selecting opioids.

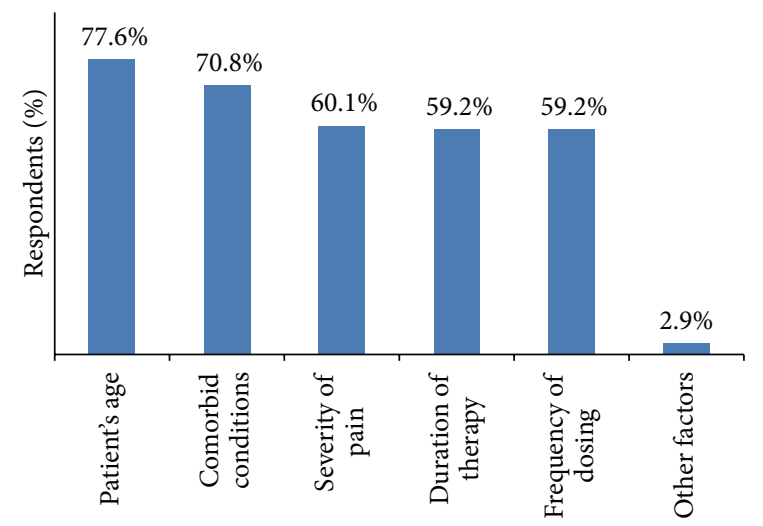

Figure 5: Factors considered by GPs while selecting NSAIDs.

Patient's age (66.9\%), comorbid conditions (42.9\%), severity of pain $(58.7 \%)$, duration of therapy $(48.9 \%)$, frequency of dosing (51.1\%), and other factors such as cost, gender, and social issues (5.26\%) were the major attributes reported by dentists for selection of NSAIDs (Figure 6).

Patient's age $(84.2 \%)$, severity of pain $(78.9 \%)$, duration of therapy (73.6\%), and frequency of dosing $(78.9 \%)$ were the major attributes shared by general surgeons during selection of NSAIDs (Figure 7).

For mild pain, paracetamol was the choice of analgesic by $77 \%$ ofGPs while for moderate pain $77 \%$ of GPs reported use of paracetamol plus tramadol combination. For the treatment of severe pain, nonspecific NSAIDs were choice of $64 \%$ of GPs. The details of other analgesics preferred by GPs for the management of mild, moderate, and severe pain are enlisted in Table 2.

Paracetamol was the choice of analgesic of $78.57 \%$ of CPs in the management of mild pain. The combination of paracetamol plus tramadol was preferred by $87.50 \%$ of CPs for the treatment of moderate pain. Nonspecific NSAIDs were preferred by $57.14 \%$ of CPs in the management of severe pain. Table 3 gives list of different analgesics used by CPs for the management of mild, moderate, and severe pain.

Nonspecific NSAIDs were preferred by $88.64 \%$ of orthopedicians for the management of mild pain. For the moderate pain, the combination of tramadol plus paracetamol was

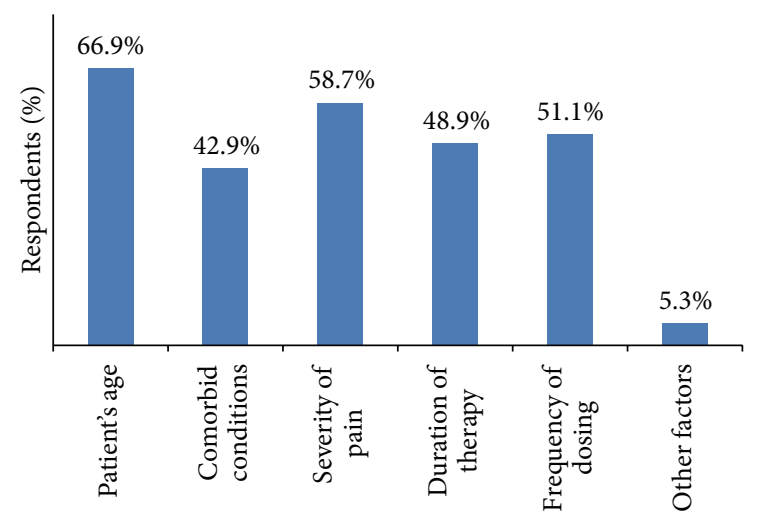

FIGURE 6: Factors considered by dentists while selecting NSAIDs.

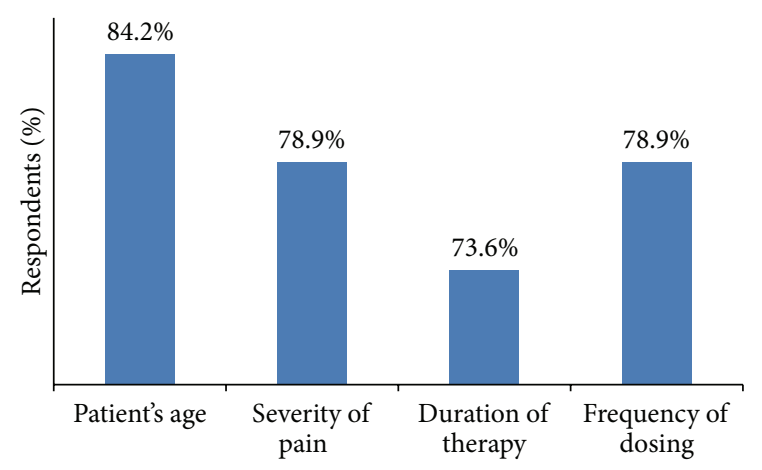

Figure 7: Attributes for the use of NSAIDs according to general surgeons.

preferred by $80.30 \%$ of orthopedicians while NSAID plus paracetamol and paracetamol plus diclofenac were favored by $68.94 \%$ and $47.73 \%$ of orthopedicians, respectively.

The list of different analgesics preferred by orthopedicians and general surgeons for the management of mild, moderate, and severe pain is given in Tables 4 and 5 .

Lack of pain clinic in the city, cost of treatment at pain clinic, and long travelling distance were commonly reported reasons for not referring the patients for pain clinics (Table 6).

Multimodal analgesia, patient controlled analgesia, referral to pain specialists, use of special techniques, and patient education and counseling were suggested by healthcare professions for better pain management (Table 7).

\section{Discussion}

Pain is one of the most common health problems for which patients seek consultation from the HCP, often after using over-the-counter medications. There is confusion about efficacy and safety of common analgesics [3] which contributes to dilemma while selecting one agent over the other. To understand different parameters considered by HPCs in reallife clinical practice while selecting an analgesic, we conducted a nationwide survey among six healthcare disciplines 


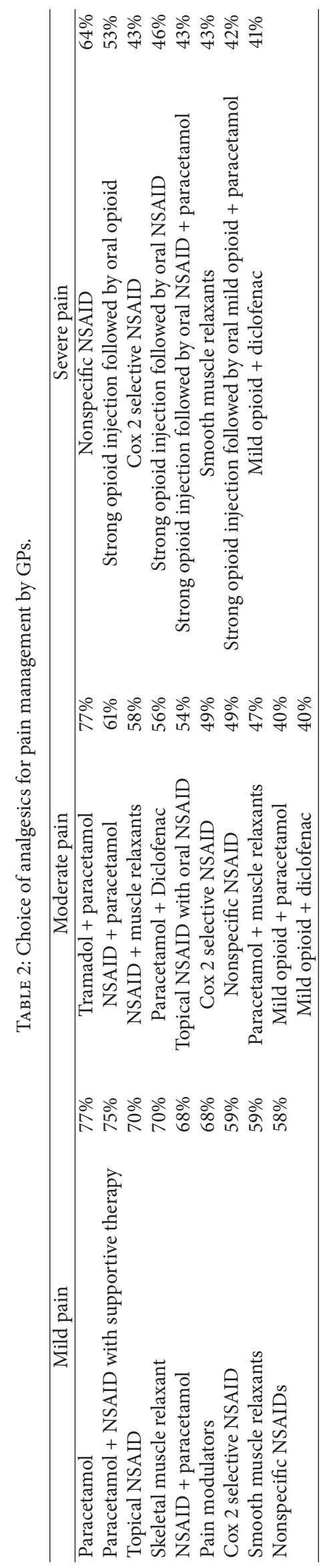




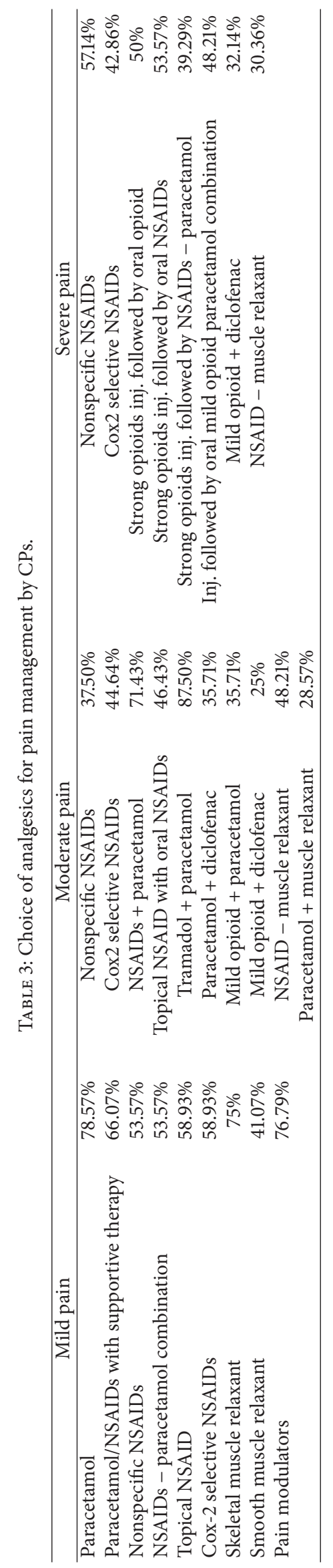




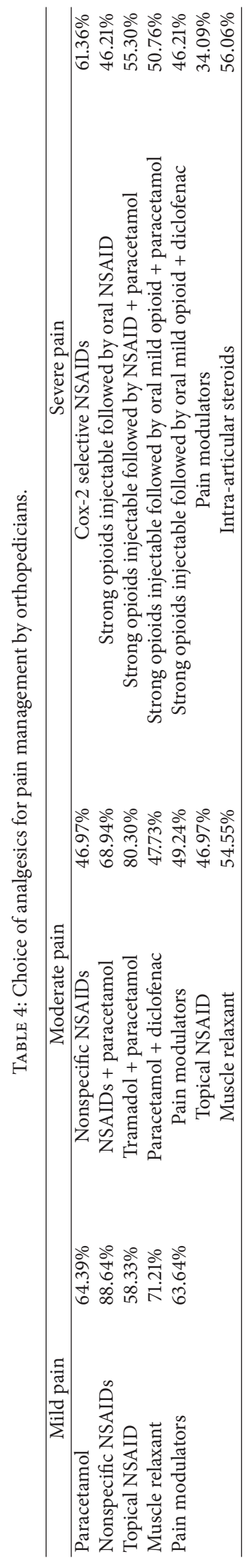


TABLE 5: Choice of analgesics for pain management by general surgeons.

\begin{tabular}{|c|c|c|c|c|c|}
\hline \multicolumn{2}{|l|}{ Mild pain } & \multicolumn{2}{|l|}{ Moderate pain } & \multicolumn{2}{|l|}{ Severe pain } \\
\hline Paracetamol & $74 \%$ & Tramadol + paracetamol & $68 \%$ & Nonselective NSAIDs & $84 \%$ \\
\hline Nonspecific NSAIDs & $68 \%$ & Pain modulators & $63 \%$ & Cox 2 selective NSAID & $53 \%$ \\
\hline $\begin{array}{l}\text { COX } 2 \text { selective } \\
\text { NSAIDs }\end{array}$ & $53 \%$ & NSAID + paracetamol & $58 \%$ & Strong opioid injection followed by oral mild opioids + paracetamol & $53 \%$ \\
\hline Antispasmodic agents & $53 \%$ & Paracetamol + diclofenac & $58 \%$ & Strong opioid injection followed by oral NSAIDs + paracetamol & $47 \%$ \\
\hline \multirow[t]{4}{*}{ Pain modulators } & $53 \%$ & Antispasmodic agents & $58 \%$ & Intra-articular steroids & $42 \%$ \\
\hline & & Nonspecific NSAIDs & $53 \%$ & Strong opioid injection followed by oral mild opioids + diclofenac & $42 \%$ \\
\hline & & Cox 2 selective NSAIDs & $47 \%$ & Strong opioid injection followed by oral NSAIDs & $42 \%$ \\
\hline & & & & Pain modulators & $32 \%$ \\
\hline
\end{tabular}

TABLE 6: Common limitations for referral to pain clinics.

\begin{tabular}{lc}
\hline Reason & $\begin{array}{c}\text { Percentage of healthcare } \\
\text { practitioners }\end{array}$ \\
\hline Lack of pain clinic in the city & $38.8 \%$ \\
Cost of treatment & $36.6 \%$ \\
Distance from home or work place & $26.1 \%$ \\
\hline
\end{tabular}

(general physicians, consulting physicians, orthopedic surgeons, general surgeons, dental clinicians, and neurologists) in India.

Patient's age was the common factor considered by all surveyed healthcare disciplines while selecting an analgesic for the management of pain. The other important criteria for analgesic selection included duration of therapy and frequency of dosing which have potential to improve the patient compliance [4]. While selecting NSAIDs, severity of pain and duration of therapy were considered equally important by most of the healthcare practitioners.

The patients seeking consultation could have another underlying systemic disease; hence careful history of comorbid conditions is important while prescribing an analgesic to avoid complications. For example, NSAIDs can cause GI, haematological, or renal adverse events [2]. Comorbid conditions were considered as an important attribute while selecting an opioid analgesic by dentists, GPs, and CPs, while GPs and dentists also consider comorbid conditions as an important attribute while selecting NSAIDs. Paracetamol is an important component of pain management [2]. It is a good alternative to NSAIDs because of less adverse events [5]. Usually it does cause adverse events except with overdosage [6]. According to the results of our study, paracetamol is the preferred analgesic for the management of mild pain by all healthcare disciplines surveyed except orthopedicians. Most orthopedicians mainly use nonspecific NSAIDs for the management of mild pain. GPs, CPs, and orthopedicians also commonly use muscle relaxants for the management of mild pain. The reason of common use of skeletal muscle relaxants by these HCPs could be related to the higher number of patients with musculoskeletal spasm visiting them compared to others.

Opioids are commonly used for treating moderate to severe pain [7]; however strong opioids are not commonly required for the management of musculoskeletal pain [8] or postoperative pain such as ambulatory hand surgery [9]. Tramadol, a synthetic, centrally acting analgesic with weak opioid agonist action, does not cause clinically significant adverse effects on respiratory or cardiovascular system at the recommended dose [10]. Analgesic combination with complementary mechanisms (e.g., tramadol plus paracetamol) is often used for better efficacy and safety compared to individual agents [9]. We observed very common use of combination therapy especially paracetamol based combination with either tramadol or NSAID in the management of moderate pain. Paracetamol and NSAIDs or tramadol act by different mechanisms and hence provide complimentary mechanisms of action to each other. Tramadol is preferred over other opioids in combination treatment due to its unique mechanism of action and better safety profile [2]. NSAIDs and selective cyclooxygenase- 2 inhibitors can reduce opioid use [11]. Recently, in Indian patients, combination of diclofenac, one of the routinely used NSAIDs with tramadol, has been shown effective and well tolerated in the management of pain because of acute musculoskeletal conditions, acute flare of osteoarthritis or rheumatoid arthritis, and postoperative pain [12].

Dental clinicians commonly select analgesics based on the pharmacodynamics and safety profile of the medicinal product [13] and use them for the management of intra-/ postoperative pain and acute/chronic pain [14]. According to our study, patients age, comorbid conditions, duration of therapy, and frequency of dosing were considered to be important factors while selecting an opioid by dentists.

According to a pan European survey among primary care physicians, use of pain assessment tools, improving confidence for using opioids, and having guidelines for the management of chronic nonmalignant pain are the areas for improvement [15]. About $8 \%$ of dental clinicians in this survey also expressed the need for national guidelines on the pain management.

Though pain clinic is an important referral center for nonresponding patients, limited access and cost are major barriers for referring patients to these clinics, according to HCPs surveyed. Patient education and counseling can influence the outcome of pain management strategies and hence should be routinely practiced according to large number of GPs, CPs, and dentists. 
TABLE 7: Suggestions by healthcare professionals for better pain management.

\begin{tabular}{|c|c|c|c|c|}
\hline GPs & CPs & General surgeons & Orthopedicians & Dentists \\
\hline $\begin{array}{l}\text { (i) Multimodal analgesia } \\
\text { (84\%) } \\
\text { (ii) Patient controlled } \\
\text { analgesia (51\%) } \\
\text { (iii) Referral to pain } \\
\text { specialists (50\%) } \\
\text { (iv) Use of special } \\
\text { techniques ( } 30 \%) \\
\text { (v) Patient education (54\%) } \\
\text { (vi) Counseling (30\%) }\end{array}$ & $\begin{array}{l}\text { Patient education } \\
(29 \%)\end{array}$ & $\begin{array}{l}\text { (i) Multimodal analgesia } \\
\text { (63.84\%) } \\
\text { (ii) Patient controlled } \\
\text { analgesia ( } 36.8 \%) \\
\text { (iii) Referral to pain } \\
\text { specialists ( } 31.57 \%) \\
\text { (iv) Use of special } \\
\text { techniques (21\%) }\end{array}$ & $\begin{array}{l}\text { (i) Multimodal analgesia } \\
\text { (83\%) } \\
\text { (ii) Patient controlled } \\
\text { analgesia (32\%) } \\
\text { (iii) Referral to pain } \\
\text { specialists (21\%) } \\
\text { (iv) Use of special } \\
\text { techniques (51\%) }\end{array}$ & $\begin{array}{l}\text { (i) Patient education } \\
\text { (45.11\%) } \\
\text { (ii) Patient counseling } \\
\text { (20.30\%) } \\
\text { (iii) Treatment guidelines } \\
(8.17 \%)\end{array}$ \\
\hline
\end{tabular}

The study holds limitations of an observational and crosssectional design. Moreover, the survey forms were provided and collected by the company representative; hence reporting bias cannot be ruled out. Nonrandom sampling may not represent the entire specialty; hence the results of this survey should be carefully extrapolated.

\section{Conclusion}

According to the findings of the present survey, patient's age, duration of therapy, comorbid conditions, frequency of dosing, and severity of pain are the main factors for the selection of analgesic. Paracetamol and paracetamol based combination are preferred for mild and moderate pain, respectively.

\section{Conflict of Interests}

All three authors are employees of Abbott Healthcare Pvt Ltd.

\section{Acknowledgments}

The authors would like to thank all doctors who participated in the survey. The authors would also like to acknowledge Mr. Anant Patil for the help in preparing the paper.

\section{References}

[1] D. S. Goldberg and S. J. McGee, "Pain as a global public health priority," BMC Public Health, vol. 11, article 770, 2011.

[2] R. B. Raffa, "Pharmacology of oral combination analgesics: rational therapy for pain," Journal of Clinical Pharmacy and Therapeutics, vol. 26, no. 4, pp. 257-264, 2001.

[3] C. J. Sachs, "Oral analgesics for acute nonspecific pain," American Family Physician, vol. 71, no. 5, pp. 913-918, 2005.

[4] J. Lin, G. E. Sklar, V. M. S. Oh, and S. C. Li, "Factors affecting therapeutic compliance: a review from the patient's perspective," Therapeutics and Clinical Risk Management, vol. 4, no. 1, pp. 269-286, 2008.

[5] M. Hyllested, S. Jones, J. L. Pedersen, and H. Kehlet, "Comparative effect of paracetamol, NSAIDs or their combination in postoperative pain management: a qualitative review," British Journal of Anaesthesia, vol. 88, no. 2, pp. 199-214, 2002.
[6] M. Donaldson and J. H. Goodchild, "Appropriate analgesic prescribing for the general dentist," General Dentistry, vol. 58, no. 4, pp. 291-297, 2010.

[7] P. Corke, "Postoperative pain management," Australian Prescriber, vol. 36, no. 6, pp. 202-205, 2013.

[8] S. A. Schug, "The role of tramadol in current treatment strategies for musculoskeletal pain," Therapeutics and Clinical Risk Management, vol. 3, no. 5, pp. 717-723, 2007.

[9] N. Rawal, V. Macquaire, E. Catalá, M. Berti, R. Costa, and M. Wietlisbach, "Tramadol/paracetamol combination tablet for postoperative pain following ambulatory hand surgery: a double-blind, double-dummy, randomized, parallel-group trial," Journal of Pain Research, vol. 4, pp. 103-110, 2011.

[10] L. J. Scott and C. M. Perry, "Tramadol: a review of its use in perioperative pain," Drugs, vol. 60, no. 1, pp. 139-176, 2000.

[11] A. Buvanendran and J. S. Kroin, "Multimodal analgesia for controlling acute postoperative pain," Current Opinion in Anaesthesiology, vol. 22, no. 5, pp. 588-593, 2009.

[12] A. S. Chandanwale, S. Sundar, K. Latchoumibady et al., "Efficacy and safety profile of combination of tramadol-diclofenac versus tramadol-paracetamol in patients with acute musculoskeletal conditions, postoperative pain, and acute flare of osteoarthritis and rheumatoid arthritis: a phase III, 5-day open-label study," Journal of Pain Research, vol. 7, pp. 455-463, 2014.

[13] F. P. Branco, M. L. P. Pinheiro, M. C. Volpato, and E. D. de Andrade, "Analgesic choice in dentistry. Part I: the mechanism of action," Brazilian Journal of Oral Sciences, vol. 4, no. 14, pp. 762-765, 2005.

[14] R. A. Dionne and C. W. Berthold, "Therapeutic uses of nonsteroidal anti-inflammatory drugs in dentistry," Critical Reviews in Oral Biology \& Medicine, vol. 12, no. 4, pp. 315-330, 2001.

[15] M. Johnson, B. Collett, and J. M. Castro-Lopes, "The challenges of pain management in primary care: a pan-European survey," Journal of Pain Research, vol. 6, pp. 393-401, 2013. 


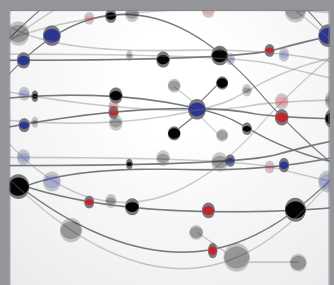

The Scientific World Journal
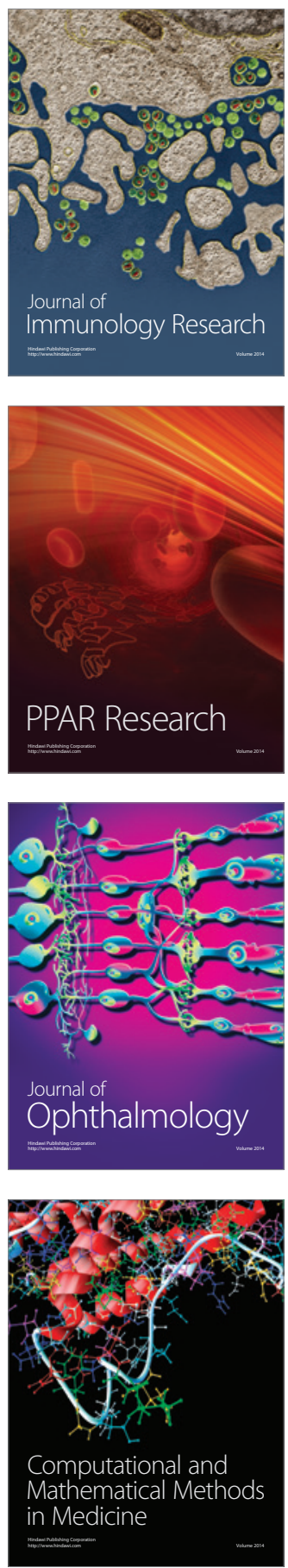

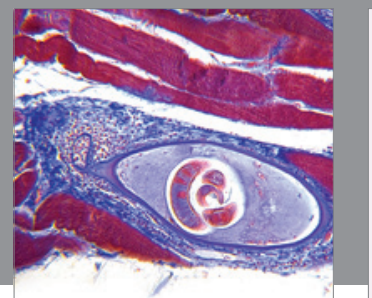

Gastroenterology

Research and Practice
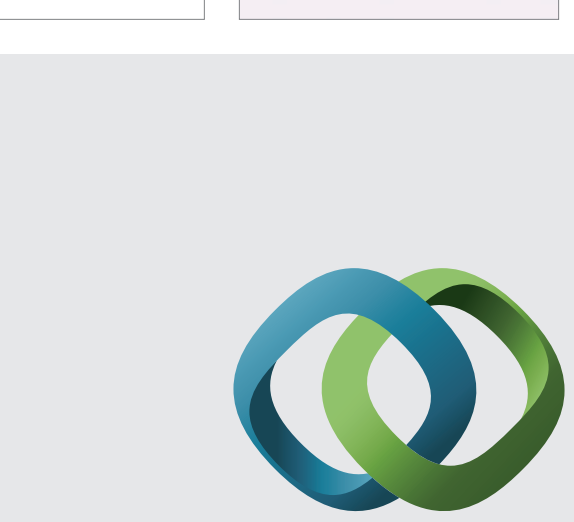

\section{Hindawi}

Submit your manuscripts at

http://www.hindawi.com
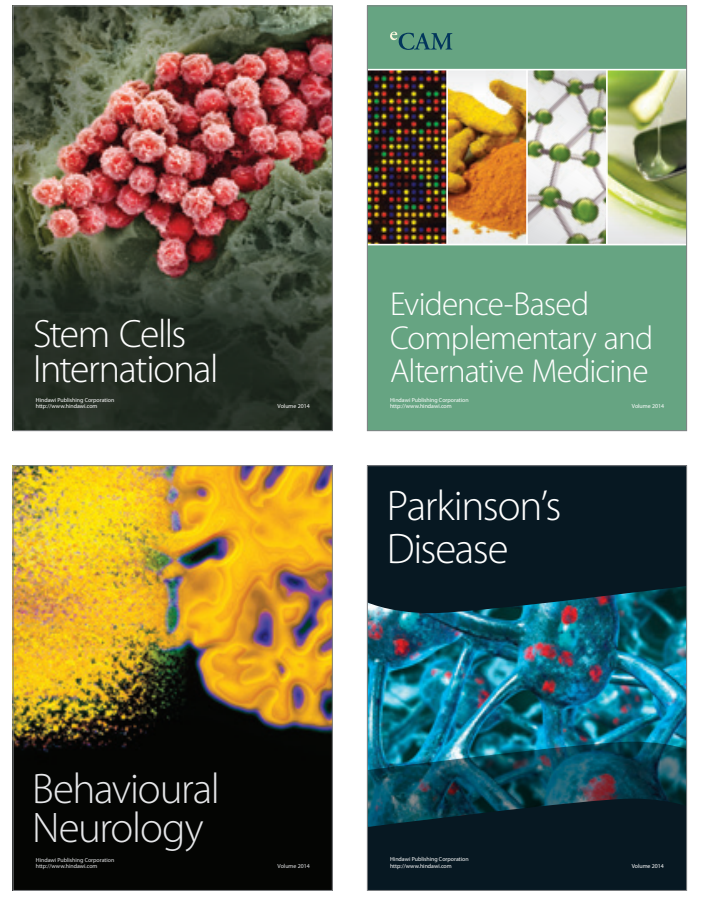
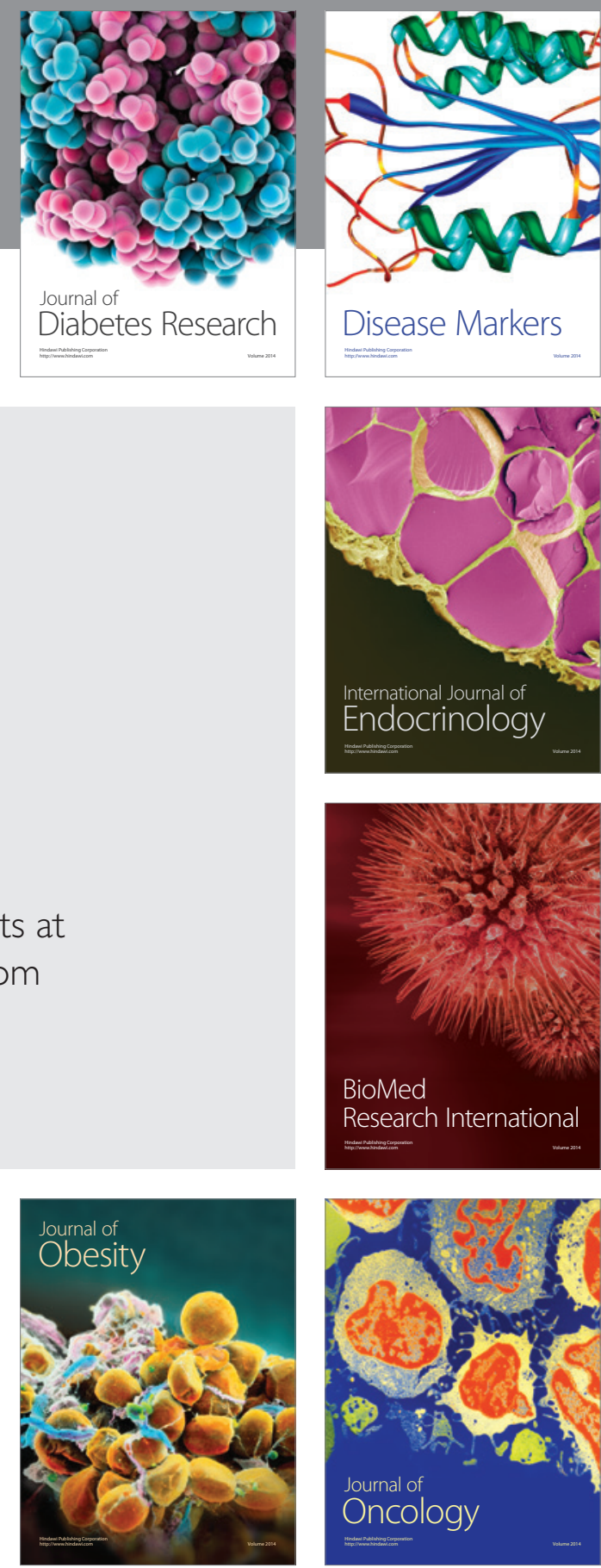

Disease Markers
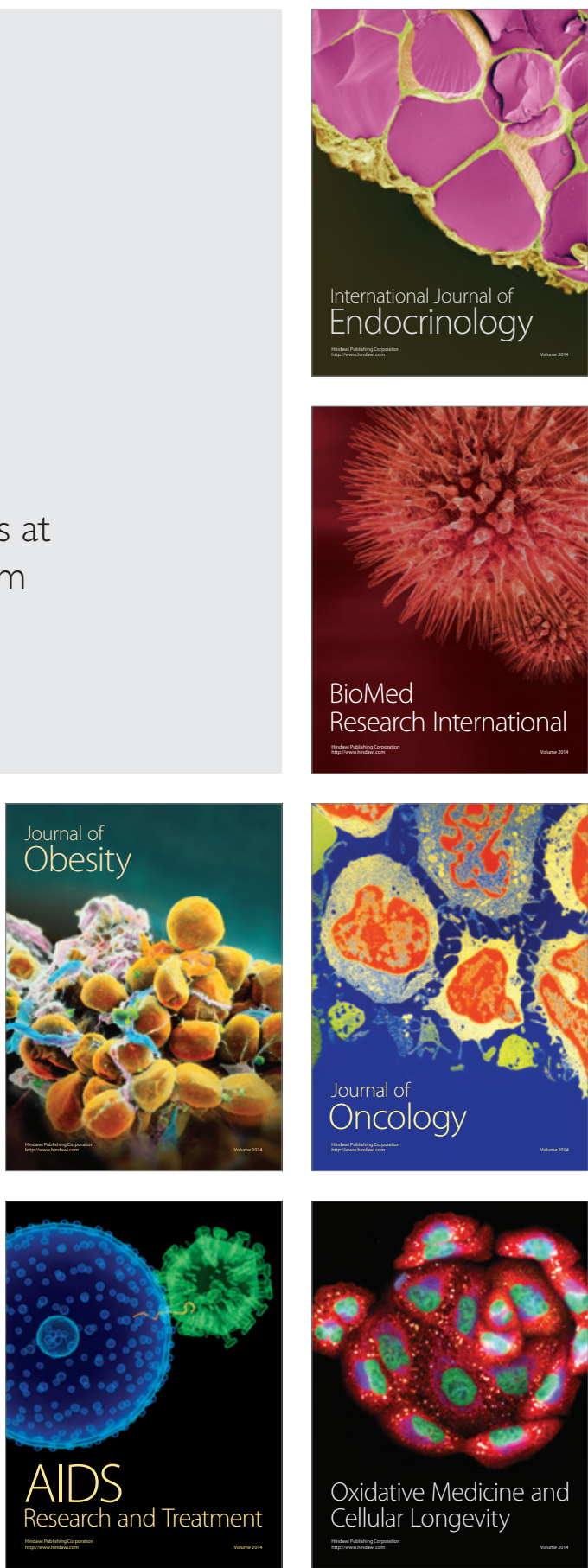